\title{
Sleeping effects in the quality of life of women with insomnia
}

\author{
Repercussões da qualidade do sono na vida de mulheres com insônia
}

\author{
Mariane Tessaro, Fabiana Magalhães Navarro-Peternella* \\ Faculdade de Ensino Superior Ingá (Uningá), Maringá, PR, Brazil
}

\begin{abstract}
Introduction: Sleeping is characterized by a temporary suspension of voluntary sensory and motor activity, regulated by the circadian cycle-and the biological clock, and any changes in their days function and general test results in poor quality of it, can affect the quality of life as a whole. Objective: To analyze the quality of sleeping in individuals with insomnia and its influence on quality of life. Methods: We interviewed 11 women from a specific questionnaire to evaluate the Quality of Sleeping Index (Pittsburgh Sleep Quality / PSQI) and one for quality of life (SF-36). Discussion: It was found that all participants had changes in sleep and quality of life was associated with tobacco use and lack of physical activity. The average found in the SF-36 was 39.0, and the most affected issues were the general health, social functioning, role physical limitations, pain and mental health. In PSQI score was obtained 13 points, indicating poor quality of sleeping and significant correlation was observed between the questionnaires, in which domains of physical functioning, vitality and social aspects showed moderate correlation. Conclusions: Poor sleeping quality can lead to compromised quality of life of individuals with insomnia.
\end{abstract}

Keywords: Quality of life. Sleeping initiation and sleeping maintenance. Sleeping Disorders.

* MT: grad, e-mail: mari_tessaro10@yahoo.com.br FMNP: grad, e-mail: navarrofabiana@gmail.com.br 


\section{Resumo}

Introdução: $O$ sono é caracterizado por uma suspensão temporária da atividade sensorial e motora voluntária, regulado pelo ciclo-circadiano e o relógio biológico, sendo que qualquer alteração que ocorra, gera sua disfunção e resulta em má qualidade do mesmo, podendo afetar a qualidade de vida como um todo. Objetivo: Analisar a qualidade do sono de indivíduos com insônia e sua influência na qualidade de vida. Materiais $\boldsymbol{e}$ métodos: Foram entrevistadas 11 mulheres, a partir de um questionário especifico para avaliar a Qualidade do Sono (Índice de Qualidade do Sono de Pittsburgh/PSQI) e outro para qualidade de vida (SF-36). Discussão: Verificou-se que todas as participantes tiveram alterações no sono e na qualidade de vida, havendo relação com uso de tabaco e a falta de atividade física. A média geral encontrada no SF-36 foi de 39,0, sendo que os domínios mais afetados foram o estado geral de saúde, aspectos sociais, limitações por aspectos físicos, dor e saúde mental. No escore do PSQI obteve-se 13 pontos, indicando distúrbio na qualidade do sono e foi observada correlação entre os questionários, no qual os domínios de capacidade funcional, vitalidade e aspetos sociais apresentaram correlação moderada. Conclusão: O distúrbio na qualidade do sono pode levar ao comprometimento da qualidade de vida dos indivíduos com insônia.

Palavras-chave: Qualidade de vida. Distúrbios do início e da manutenção do sono. Transtornos do sono.

\section{Introduction}

Sleeping is characterized by a temporary suspension of sensory and motor activity, being a behavioral complex state and one of the great mysteries of modern neuroscience. Its disorders are increasingly related to symptoms of depression, and they can achieve around $80 \%$ of cases, but when the disorder is the hypersomnia, this way the increase in inactivity, this percentage drops to approximately $20 \%$, being more related to hiposonia, which refers to the reduced time of sensory inactivity (1).

There are two processes related to sleeping, the circadian cycle and the biological clock. The first process relates to an internal 24 hours clock, located in the hypothalamus, which regulates sleeping time and consolidates the sleeping-wake cycle, controlled by the central nervous system (CNS). The biological clock regulates the secretion of hormones such as growth and prolactin and stimulating hormone thyroid (TSH) $(2,3)$.

Any change that occurs in such regulators may be considered as a sleeping disorder, which is classified into two major groups, parasomnias and dyssomnias. In the first condition, and peculiar behavior events occurring during sleeping can lead to daytime sleepiness or non-restorative sleep, and the dyssomnias, disorders produce a difficulty in initiating or maintaining sleeping time, which refers to insomnia, characterized by a nocturnal sleeping disturbed or upset waking (4).
Insomnia is considered a chronic disease, because it interferes in the professional life of the individual (5), family and social, making it unable to respond to external stimulation, causing difficulty in concentration and precluding numerous activities of daily routine (2-6), which commits a lot the quality of life (QOL). Quality of life refers to a satisfaction in family life, loving, social and environmental, involving the individual's perception of their health status. As the determinants of the health-disease are multifactorial and complex, health and disease configure processes related to economic, socio-cultural, personal experience and lifestyle $(7,8)$.

Women become the target of research related to quality of life, because they assume a care and work routine. Their experience with hormonal changes bring numerous symptoms such as menstrual cycle changes, vasomotor, depressive symptoms and sleeping disorders that impair the routine and quality of life (3-9). In a study of Palhares et al. (5) with nursing professionals, they found an association of poor sleeping quality in women and a strong correlation between the quality of life and the quality of sleeping.

Thus, there is an association between poor quality of sleeping, health and wellness (10) stressing the importance of good sleeping maintenance to improve the daily performance. Some studies aim to describe the neurobehavioral performance of sleeping, other metabolic consequences of sleeping disorders back to the patient and also those who seek to know cardiovascular insomniacs health (11). 
Caska et al. (12) reported that a poor sleeping quality can be associated with coronary artery disease thus understand the poor quality of sleep and modify it, you can minimize morbidity and mortality in patients with coronary heart disease. In addition to demonstrating an older age, female gender, nonwhite race, lower education, lower income and single marital status, as major risk factors for the development of insomnia. Such reports praise the importance of knowledge and studying as alternative ways to treat insomnia, and physical therapy brings great features and techniques that promote deep relaxation and provide a successful outcome without risks to patients, without causing side effects, improving not only the quality of sleeping, but also the quality of life. However, it is necessary to better understand the factors and areas most affected by this disease to guide treatment more effectively $(13,14)$.

In this way, the need to seek more information about the quality of life and sleeping of women with insomnia was originated, checking for a relationship between age, smoking, alcohol consumption, physical activity, obesity and chronic diseases and/or involving psychic issues. Thus, the aim of this study was to watch carefully the correlation between sleeping quality with the quality of life from women with insomnia, in order to direct better physical therapy approaches.

\section{Methods and materials}

It was conducted a cross-sectional study with patients from the doctor's office and sleeping laboratory in the city of Maringá in the state of Paraná, whose presented clinical doctor's diagnosis of insomnia. During 30 days all patients with this diagnosis and who were under medical treatment at this time were approached. The same amount was invited to participate in the survey, and from the 20 addressed, only 11 have expressed interest, which received all ethical research information, and proceeded to schedule a personal interview at the clinic mentioned, in a closed environment for individuality and protection data. As all of them were in clinical treatment, there were no exclusion factors beyond research participation of refusal or inability to understand the questionnaires.

In this interview two structured questionnaires and an evaluation form with general data characterizing the sample were applied, and the age, sex, weight, height, BMI (body mass index), marital status, education level, profession, history of disease, smoking, alcohol consumption, physical inactivity, comorbidities, medications, type of insomnia, previous treatments and sleeping position. Besides that two open questions were added asking what do the patient think of his/her sleeping and insomnia which could disturb the quality of life and sleeping.

The questionnaire used was the SF-36 and the Pittsburgh Index. The SF-36 evaluates the quality of life, composed of eight domains measuring different areas of health: physical function, physical performance, physical pain, general health, mental health, emotional role, social function and vitality, each of it has a score that varies from zero (0) to one hundred (100), and the lower the score is the worse is the quality of life (15). Sleeping Quality Index in Pittsburgh (PSQI) evaluates the quality of sleeping compared to the last month, being able to distinguish "good sleepers" patients from "bad sleepers" ones. The questionnaire consists of 19 self-administrative issues, which are grouped into seven components, and the subjective sleeping quality, sleeping latency, sleeping duration, habitual sleeping efficiency, sleeping disturbances, use of sleeping medication and daytime dysfunction, and assigned from zero to three points to each question, resulting in a final score from zero to 21 points, where the higher the score, the worse the quality of sleeping (2).

After realizing the interviews, the data were tabulated and analyzed by SPSS statistical software version 17.0 through descriptive data with medium scores, standard deviations and interquartile stops, as well as Shapiro-Wilk test to verify the normality of data and Spearman correlation, considering $\mathrm{p}<0.05$ significance. There was the approval by the Ethics and Research Committee on Human Beings of the Higher Education Unit Inga - UNINGÁ, by the feedback 301,327 . There was no funding source for this study.

\section{Results}

The survey participants were a total of eleven women about 39.5 years old. From these total, only four did not use drugs and three had conducted some alternative treatment for insomnia, like micro physical therapy, acupuncture and psychotherapy. These alternative therapy techniques include cognitive-behavioral, educational and sleeping hygiene, 
stimulus control therapy, restriction therapy, paradoxical intervention, relaxation therapy, and sleeping consolidation (16). Investigating the presence of other diseases, one reported having high blood pressure; hyperthyroidism and two other participants reported depression.

According to Table 1, we observed that most of the sample (72.7\%) was married and did not exercise any occupation; two did not exercise at all. In relation to sleeping, $63.6 \%$ of these women had trouble falling asleep and $36.4 \%$ difficulty initiating and maintaining the sleeping condition. It was also observed that most had normal BMI (54.4\%), followed by $27.2 \%$ overweight and only $9.1 \%$ with grade III obesity.

Table 1 - Characteristics of individuals with sleep disorders, Maringá-PR.

(to be continued)

\begin{tabular}{|c|c|c|}
\hline Variables & N & $\%$ \\
\hline \multicolumn{3}{|l|}{ Marital status } \\
\hline Married & 8 & 72.7 \\
\hline Single & 1 & 9.1 \\
\hline Widow & 2 & 18.1 \\
\hline \multicolumn{3}{|l|}{ Occupation } \\
\hline Merchant & 1 & 9.1 \\
\hline Advertsing & 1 & 9.1 \\
\hline Teacher & 1 & 9.1 \\
\hline Non Working & 8 & 72.7 \\
\hline \multicolumn{3}{|l|}{ Smoking } \\
\hline Yes & 2 & 18.1 \\
\hline No & 9 & 81.8 \\
\hline \multicolumn{3}{|l|}{ Alcoholism } \\
\hline Yes & 0 & 0 \\
\hline No & 11 & 100 \\
\hline \multicolumn{3}{|l|}{ Physical activity } \\
\hline Yes & 5 & 45.4 \\
\hline No & 6 & 54.5 \\
\hline
\end{tabular}

Table 1 - Characteristics of individuals with sleep disorders, Maringá-PR.

\begin{tabular}{lcc} 
& & (conclusion) \\
\hline \multicolumn{1}{c}{ Variables } & N & $\%$ \\
\hline BMI (body mass index) & & \\
$\quad$ Below weight & 1 & 9.1 \\
Eutrophic & 6 & 54.5 \\
Overweight & 3 & 27.2 \\
Obesity I & 0 & 0 \\
Obesityll & 0 & 0 \\
Obesity III & 1 & 9.1 \\
\hline
\end{tabular}

Regarding the sleeping position, seven participants reported sleeping in the lateral position, two prone, one supine and one interviewed did not specify a fixed sleeping position as rolled all night without keeping a stable one. The interviewees self-classified their sleep, and three said their sleep was bad six that his sleep was bad, and two that sleep was regular. Those who mentioned the bad and worse situation reported to wake up at night and cannot get back to sleep, a fact that hurts professional and daily activities very much on the following day, instead of those who reported regular sleeping condition; they related the use of medication to a good sleeping.

In total, the interviewed ones said that the poor quality of sleeping interferes with quality of life as their not sleeping well to their limited daily activities, leaving them unwilling, nervous, stressed and discouraged.

Related to Table 2, we notice that the average overall score of the SF-36 was 47.1 ( \pm 16.6 ). Looking at the components, we observed that the worst score obtained in this study was the role emotional, with an average of $31.0( \pm 40.0)$, and the best score achieved was given according to the general state of health domain, averaging 65.0 ( \pm 16.1 ), followed by social, limitations on physical aspects, pain and mental health. Regarding PSQI, the average achieved in this study was 13 points $( \pm 2.44)$ and the maximum score for this is 21 points, just to conclude the higher the score, the worse the quality of sleeping. Thus, scores with results greater than five, indicate that the individual presents great difficulties in at least two components or moderate difficulty in up to three components (Table 2). 
Table 2 - Standard deviation of the average related to age, SF-36, SF-36 components and Sleeping Quality Index in Pittsburgh, Maringá-PR.

\begin{tabular}{lcc}
\hline \multicolumn{1}{c}{ Variables } & $\begin{array}{c}\text { Average } \\
\text { (standard } \\
\text { deviation) }\end{array}$ & (Q1:Q3) \\
\hline Age & $39.0( \pm 14.5)$ & $35(31: 41)$ \\
Total SF-36 & $47.1( \pm 16.6)$ & $48(33: 53)$ \\
$\quad$ Functional Capacity & $44.0( \pm 5.8)$ & $45(40: 50)$ \\
$\quad$ Limitation by & $50.0( \pm 31.6)$ & $50(27: 75)$ \\
$\quad \begin{array}{l}\text { Physical aspects } \\
\text { Pain }\end{array}$ & $48.6( \pm 30.9)$ & $50(10: 74)$ \\
$\quad$ General Health & $65.0( \pm 16.1)$ & $61(52: 76)$ \\
$\quad$ Vondition & $38.1( \pm 22.8)$ & $40(20: 50)$ \\
$\quad$ Vitality & $56.6( \pm 22.6)$ & $50(37: 75)$ \\
$\quad$ Limitation by & $31.0( \pm 40.0)$ & $10(0: 66)$ \\
emotional aspects & $46.9( \pm 19.6)$ & $48(24: 64)$ \\
$\quad$ Mental Health & $13.0( \pm 2.4)$ & $14(11: 15)$ \\
\hline \begin{tabular}{l} 
PSQI \\
\hline
\end{tabular}
\end{tabular}

Analyzing the SF-36 and their domains with the PSQI, it was found that there was a moderate correlation. Between the domains, it was observed that the functional capacity, vitality, and social aspects have a moderate degree of PSQI relation to and between other areas the correlation is weak.

Table 3 - Correlation between quality of life and sleeping quality in patients with insomnia.

\begin{tabular}{|c|c|c|}
\hline Variables & $\mathbf{R}$ & $\begin{array}{c}\text { Relation } \\
\text { degree }\end{array}$ \\
\hline General SF-36 & -0.40 & Moderate \\
\hline Functional Capacity & -0.50 & Moderate \\
\hline $\begin{array}{l}\text { Limitation by } \\
\text { Physical aspects }\end{array}$ & -0.33 & Weak \\
\hline Pain & -0.14 & Weak \\
\hline $\begin{array}{l}\text { General Health } \\
\text { Condition }\end{array}$ & -0.30 & Weak \\
\hline
\end{tabular}

Table 3 - Correlation between quality of life and sleeping quality in patients with insomnia.

(conclusion)

\begin{tabular}{lcc}
\hline \multicolumn{1}{c}{ Variables } & $\mathbf{R}$ & $\begin{array}{c}\text { Relation } \\
\text { degree }\end{array}$ \\
\hline Vitality & -0.49 & Moderate \\
$\begin{array}{l}\text { Social Aspects } \\
\text { Limitation by } \\
\text { emotional aspects }\end{array}$ & -0.65 & Moderate \\
\begin{tabular}{l} 
Mental Health \\
\hline
\end{tabular} & 0.03 & Weak \\
\hline
\end{tabular}

\section{Discussion}

Changes in sleeping and wakefulness negatively affect on mood, in memory and psychomotor performance of the individual, reflecting directly on their quality of life (17). In this study was relevant the number of interviewed who were using drugs, but few sought non-pharmacological treatment, isolated or associated to drug. According to Cavadas and Ribeiro (16), there are evidences of combinations of specific pharmacological treatment to nonpharmacological treatment from the cognitive behavioral therapy; this treatment may be useful in secondary insomnia, helping to treat the underlying disease. Pharmacological interventions have a faster response; however, its effectiveness improves when combined with other non-pharmacological therapy, which encourages relaxation and improved sleeping. Although few reported having depression associated with, this and other psychiatric disorders, have been increasingly relating with insomnia, although you need to find out what is the primary disease, coming from many cases insomnia can be a secondary factor to depression, coming from a side effect of antidepressant medications (16).

The characterization of the sample found this parallel data in a reliability analysis study and reproducibility of the Sleeping Habits Questionnaire in identifying sleeping disorders, studying 70 patients with insomnia and excessive sleepiness, as well, the average age found in this study was 40.4 years, $63.4 \%$ of this sample were female and most of them were married or in stable relationships (62.9\%) (18). In another study, it was studied 158 individuals, of whom $72 \%$ were female and $51 \%$ had a companion with prevalent age group 60-69 years (19). No 
correlation to justify the fact that the prevalence of having studied a companion, and the fact that they do not have any occupation at the time of data collection was observed, according to Cavadas and Ribeiro (16), there are indications that the stress could be a precursor to insomnia, and this occurs due to a professional occupation.

Some studies have shown a strong presence of insomnia among women in menopausal period, due to stressors, family burden and work $(20,21)$. But a recent study of Robaina (22) found that insomnia, reflected the difficulty in falling asleep and staying asleep, being like this independent of socioeconomic, demographic and psychosocial factors, suggesting independence of that association in relation to other factors also prevalent in this phase of life and associated with menopause.

Among the interviewed, few practiced regular physical activity, and the fact is that exercise improves sleeping quality and should be practiced in the morning or afternoon, as if they are carried out close to bedtime can disrupt sleeping quality (23). The frequency of physical activity can influence the quality of sleeping, this way a low level of physical activity seems to be one of the factors that can worsen sleeping quality (24).

Smoking has also been found, even though this is a stimulant related to sleeping disorders, as well as the use of other drugs and alcohol, which were not found in this study, but they affect sleeping quality by acting directly on the central nervous system, causing their user to be on alert condition (4-25). Thus, it is necessary to stimulate and encourage changes in lifestyle, such as regular exercise and not using tobacco and alcohol, these changes besides reflecting the numerous body systems, will improve sleeping quality and the decrease of dependence on medication to sleep.

Only one of the interviewed showed a high BMI, featuring obesity, however, even with the highest score in the PSQI of this study and the second lowest in the SF-36, it cannot infer any relation between insomnia and obesity, but Correa et al. (9) observed high prevalence of sleeping-disordered breathing, fragmented sleeping and early insomnia and increased incidence of thyroid disorders in the group with higher BMI.

The difficulty in initiate sleeping, referring to a longer delay than 30 minutes to fall asleep, and the difficulty of initiating and maintaining sleeping condition, awaken fact more than twice a night, taking a longer time than five minutes to fall asleep every awakening are aspects directly related to the quality of sleeping, leading to disabilities to enjoy the family and social relationships, it is proved that the greater the number of sleepless nights per month, the lower the productivity and concentration, reaching directly in activities of daily living.

Regarding quality of life, the worst score obtained in this study was the role emotional and the best was for the general health condition, followed by social, limitations on physical aspects, pain and mental health. These results are given by the fact that insomnia leads to symptoms of fatigue, depression, concentrating difficulty, memorizing difficulty data and the lack of attention, they relate to the domains that were mentioned before (2).

In assessing the quality of sleeping, we also find a great commitment to all of its components, which are sleeping quality, sleeping latency, sleeping duration, sleeping efficiency, sleeping disturbances, use of medications to sleep and daily disorders.

Analyzing it individually, it was compromised that quality of life and quality of sleeping of these sleepless women became clear, and in addition to it, we found a moderate correlation between these instruments, especially with regard to functional capacity, vitality and social aspects, explaining again how the quality of sleeping greatly affects the lives of these individuals.

Comprehending the importance of investigating sleeping disorders has been increasing as the points of the relevant research aspects in this study were shown, due to the clinical conditions which affected this condition. The correlation of sleeping disorders with health professionals have already been found (5), rheumatic patients (26), fibromyalgia (27) elderly subjects (28), in all cases the quality of life is greatly affected. Thus, you must enter the insomniacs in physical therapy treatments that seek a global muscle relaxation and balance, like Tai Chi, Yoga, Meditation, acupuncture, aroma-therapy massage (12), hydrotherapy (29) Pilates (30), among others technical resources and aiming for muscle relaxation and emotional stress to be released.

\section{Conclusion}

The quality of life of women has changed, and their sleeping quality as well, which resulted in a 
more specific impairment of functional capacity, vitality and social aspects. Knowing the areas most affected by insomnia, health professionals must come together to seek and provide an improvement in all aspects of these insomniacs.

Physiotherapy comes in another important field of activity in which the physiotherapist exercises a key role in maintaining a quality of sleeping and quality of life. However, to establish this importance, other studies with more representative samples are necessary as well and studies comparing the quality of life and sleeping among patients groups with insomnia compared to non-carrier, in order to investigate whether changes are actually likely related with sleeping or if there may be other related factors.

\section{References}

1. Moraes WAS, Burke PR, Coutinho PL, Guilleminault C, Bittencourt AG, Tufik S, et al. Sedative antidepressants and insomnia. Rev Bras Psiq. 2011;33(1):91-5.

2. Bertolazi AN, Fagondes SC, Hoff LS, Pedro VD, Barreto SSM, Johns W. Portuguese-language version of the Epworth sleepiness scale: validation for use in Brazil. J BrasPneumol. 2009;35(9):877-83.

3. Saus E, Soria V, Escaramis G, Vivarelli F, Crespo JM, Kagerbauer B, et al. Genetic variants and abnormal processing of pre-miR-182, a circadian clock modulator, in major depression patients with late insomnia. Human Molecular Genetics. 2010;19(20):4017-25.

4. Pinto LR, Alves RC, Caixeta E, Fontenelle JA, Bacellar A, Poyares D, et al. New guidelines for diagnosis and treatment of insomnia. Arq Neuropsiquiatr. 2010; 68(4):666-75.

5. Palhares VC, Conte JE, Matsubara BB. Association between quality of sleeping and quality of life of nursing professionals who work in shifts. Public Health. 2014;48(4):594-601.

6. Henrique Filho PSA, Pratesi R. A possible cause of attention deficit in children and adolescents with Chiari malformation type II. Arq Neuropsiquiatr. 2009;67(1):29-34.

7. Silveira RE, Reis NA, Santos AS, Borges MR. Quality of life of teachers in primary education at a Brazilian town. Rev. Enf. Ref. 2011 jul;3(4).
8. Simeão SFAP, Minatel F, Vitta A, Gatti MAN, Conti MHS, Marta SN, et al. Quality of life of high school students. SALSUVITA: Bauru. 2012;31(2):153-68.

9. Corrêa KM, Cittencourt LRA, Tufik S, Hachula H. Frequency of sleeping disorders in postmenopausal women with overweight/obesity. Rev Bras Ginecol Obstet. 2014;36(2):90-6.

10. Listsenburg VRL, Huisman J, Hoogerbrugge PM, Egeles RM, Kspers GJL, Gemke RJBJ. Impaired sleep affects quality of life in children during maintenance treatment for acute lymphoblastic leukemia: an exploratory study. Health and Qual Life Outcomes. 2011;9:25.

11. Grander MA, Patel NP, Gehrman PR, Perlis ML, PackAI. Problems associated with short sleep: bridging the gap between laboratorial and epidemiological studies. Sleep Med Rev. 2010;14(4):239-47.

12. Caska CM, Hendrickson BWMH, Ali S, Neylan T, Whooley MA. Anger expression and sleep quality in patients with coronary heart disease: findings from the heart and soul study. Psychosom Med. 2009; 71(3):280-5.

13. Passos GS, Tufik S, Santana MG, Poyares D, Mello MT. Non-pharmacological treatment for chronic insomnia. RevBras Psiquiatr. 2007.

14. Gooneratne NS. Complementary and alternative medicine for sleep disturbances in older adults. Clin Geriatr Med. 2008 February; 24(1):121-viii.

15. Severo M, Santos AC, Lopes C, Barros H. Reliability and validity of theoretical concepts of physical and mental health dimensions of the Portuguese version of the MOS SF-36. Acta Med Port. 2006;19:281-8.

16. Cavadas LF, Ribeiro L. Approach of secondary insomnia. Acta Med Port. 2011;24:135-44.

17. Silva e Costa ZMS, Pinto RMC, Mendonça TMS, Silva CHM. Translation and cultural adaptation for the Portuguese language domains sleeping disorders and Disorders of Wake's Patient-Reported Outcomes Measurement Information-System (PROMIS). Cad. Public Health. 2014;30(7):1391-401.

18. Chellappa SL, Araújo JF. Reliability and reproducibility of Sleeping Habits Questionnaire in depressed outpatients. Rev Psiq Clín. 2007;34(5):210-4. 
19. Oliveira BHD, Yassuda MS, Curpertino APFB, Neri AL. Relation between sleeping pattern, perceived health and socioeconomic variables in a sample of elderly community residents - THINK Study. Science \& Group Health. 2010;15(3):851-60.

20. Pérez JAM, Garcia FC, Palacios S, Pérez M. Epidemiology of risk factors and symptoms associated with menopause in Spanish women. Maturitas. 2009;62: 30-6.

21. Hachul H, Brandão LC, Bittencourt LRA, D’Almeida $\mathrm{V}$, Andersen ML, Baracat EC, et al. Clinical profile of menopausal insomniac women referred to sleep laboratory. Acta Obstet Gynecol Scand. 2009;88:422-7.

22. Robaina JR, Lopes CS, Rotemberg L, Foerstein E. Psychosocial and socioeconomic factors related to insomnia and menopause: Pro-Health Study Cad. Saúde Pública. 2015;31(3):597-606.

23. Orlandi AC, Ventura C, Gallinaro AL, Costa RA, Lage LV. Pain improvement, fatigue and subjective sleeping quality through sleeping hygiene guidelines in patients with fibromyalgia. Braz Reumatol. 2012;52(5):666-78.

24. Campos RMS, Silva A, Queiroz SS, Mônico NM, Roizenblatt S, Tufik S, Mello MT. Fibromyalgia: physical activity level and sleeping quality. Motriz Pysical Education. 2011;17(3):468-76.

25. Chiaperri N, Serbena CA. The consumption of alcohol, tobacco and drugs by students in the area of health in the University of Curitiba. Psychology: reflection and criticism. 2007;20(2):303-13.

26. Aydin E, Bayraktar K, Turan Y, Omurly I, Tastaban E, Sendur OF. Sleeping quality in patients with ankylosing spondylitis. Bras Reumatol. 2015. [Cited in 2014 Dec 07]. Avalaible from: http://dx.doi.org/10.1016/j. rbr.2014.12.007.
27. Avila LA, Araujo Filho GM, Guimarães EFU, Gonçalves LCS, Paschoalin PN, Aleixo FB. Characterization of the patterns of pain, sleeping and alexithymia in patients with fibromyalgia treated at a tertiary Brazilian center. Braz Reumatol. 2014;54(5):409-13.

28. Mansano-Schlosser TC, Santos AA, CamargoRossignolo SO, Freitas DCCV, Lorenz UR, Ceolim MF. Institutionalized elderly: chronological organization of daily routines and sleeping quality. Braz Nursing. 2014;67(4):610-6.

29. Agra KOA, Araújo KMB, Carvalho SMCR, Barreto JM, Oliveira EA. The aquatic therapy as a coadjuvant in the range of mood in postmenopausal women. Bras Science \& Health. 2013;17(4):327-34.

30. Vasconcelos MHO, Silva RDS, Santos SMB, Merlo JRC, Conceição TMA. The Pilates ${ }^{\circledR}$ Method in the treatment of lower back pain. Rev Fisiot Movimen. 2014;27(3):459-67.
Received: $10 / 28 / 2013$

Recebido: 28/10/2013

Approved: 05/12/2015

Aprovado: $12 / 05 / 2015$ 